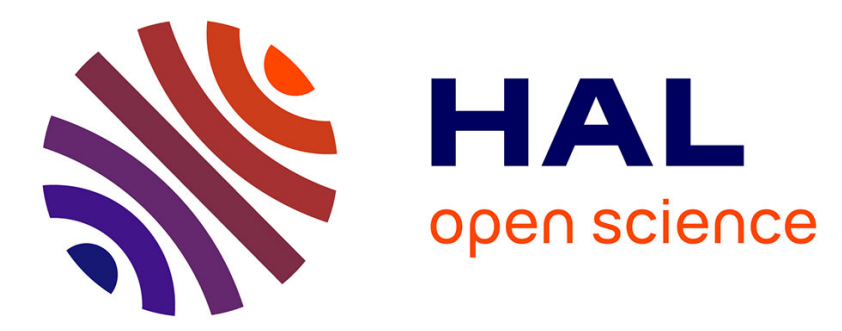

\title{
Colored Petri Net Model of IEC Function Block and Its Application
}

Zhi Wang, Fang Huang, Youxian Sun, Ye-Qiong Song

\section{To cite this version:}

Zhi Wang, Fang Huang, Youxian Sun, Ye-Qiong Song. Colored Petri Net Model of IEC Function Block and Its Application. 9th IEEE International Conference on Emerging Technologies and Factory Automation 2003 - ETFA'2003, 2003, Lisbonne/Portugal, 4 p. inria-00107714

\section{HAL Id: inria-00107714 https://hal.inria.fr/inria-00107714}

Submitted on 19 Oct 2006

HAL is a multi-disciplinary open access archive for the deposit and dissemination of scientific research documents, whether they are published or not. The documents may come from teaching and research institutions in France or abroad, or from public or private research centers.
L'archive ouverte pluridisciplinaire HAL, est destinée au dépôt et à la diffusion de documents scientifiques de niveau recherche, publiés ou non, émanant des établissements d'enseignement et de recherche français ou étrangers, des laboratoires publics ou privés. 


\section{Colored Petri Net Model of IEC Function Block and Its Application}

\author{
Zhi Wang Fang Huang Youxian Sun \\ National Laboratory of Industrial Control Technology \\ Zhejiang University, Zheda Road 38, \\ Hangzhou, 310027, China \\ *Author of correspondence: wangzhi@iipc.zju.edu.cn
}

Yeqiong Song

LORIA-ENSEM

2, av. de la Forêt de Haye

Vandoeuvre-lès-Nancy, 54516, France

or zhiwang iipc@yahoo.com

\begin{abstract}
A CPN based IEC FB model and its application are introduced in this paper. The model not only can analyze the internal procedure of IEC FB, especially the parameter's status propagation and the mode's switch, but also can be integrated into modeling IEC FB application. The latter is explained with a FB application, FB based boiler water level control system.
\end{abstract}

\section{Introduction ${ }^{1}$}

With the publish of IEC 61558 and evolving IEC 61499 and 61804 , control system comes to a new generation-networked control system. In the networked control system, sensor, actuator and controller are connected with each other using networks to achieve some common function ${ }^{[1-4]}$. In the developing of this new kind of control system, IEC FB (function block), such as IEC 61558, 61499 and 61804, plays important roles. IEC FB defines basic concepts and methodology for design of modular, re-useable, distributed industrial process measurement and control systems (IPMCSs) ${ }^{[5]}$. IEC FB construct is defined as an abstraction mechanism that allows industrial algorithm to be encapsulated in a form which can be easily understood and applied by industrial engineers who are not specialists in the complicated algorithms ${ }^{[6-8]}$. IEC FB has get focus from lots of aspects, such as design model, verification technology, support tool, et.al $\mathrm{l}^{[1,2,5,6,7,8,12,13]}$

IEC FB is characterized by its capability of autodiagnosis and adaptability with the help of parameter's status and mode. Within FB, fault redundant is automatically implemented without any operator's interference in case for example, sensor failure or communication failure. Since a fault state is indicated with mechanism of parameter's status propagation, and in sequence a safety style is changed into with mode switch ${ }^{[3][4][5]}$. However, for the lack of normal description of the mechanism of parameter's status propagation and the mode switch, the internal procedure of FB can't be comprehended clearly. Hence, it is necessary to describe FB with graphical and mathematical tools, which can redound to the realization of FB.

For the above reasons, a CPN (colored Petri net) ${ }^{[10]}$ based FB model, which not only graphically simulate, but also normally analyze the procedure of IEC FB, is given in this paper.

\section{IEC FB based IPMCSs}

Particularly dedicated to the software re-usability issue, modularity, encapsulation, IEC FB is defined. In industrial system, IEC FB is a well-established concept for defining robust, re-usable software component to meet the different requirements of automated manufacturing and process control function. IEC FB represents the automation function,

\footnotetext{
${ }^{1}$ This work is supported by PRA-S101-04 and NSFC-60203030 and 60084001
}

such as data acquisition, performed by an application, which are as independent as possible of the specifics of $\mathrm{I} / \mathrm{O}$ devices and networks.

\subsection{Function Block Application}

According to IEC standard, FB application is defined as industrial application which implements one or more automation function. The fundamental model to construct FB applications is FB. To support IPMCSs, IEC provides a collection of $\mathrm{FB}$, interconnected and communicated with each other by mean of FB service. Each FB is an independent physical entity capable of performing one or more specified function in a particular context and delimited by its interface. These devices perform a portion of the total system operation by implementing one or more time critical application or portions of the application, such as sensor data acquisition and control algorithm processing. Each FB application is composed of a set of FBs, which reside on a common fieldbus network, as shown in the Fig.1.

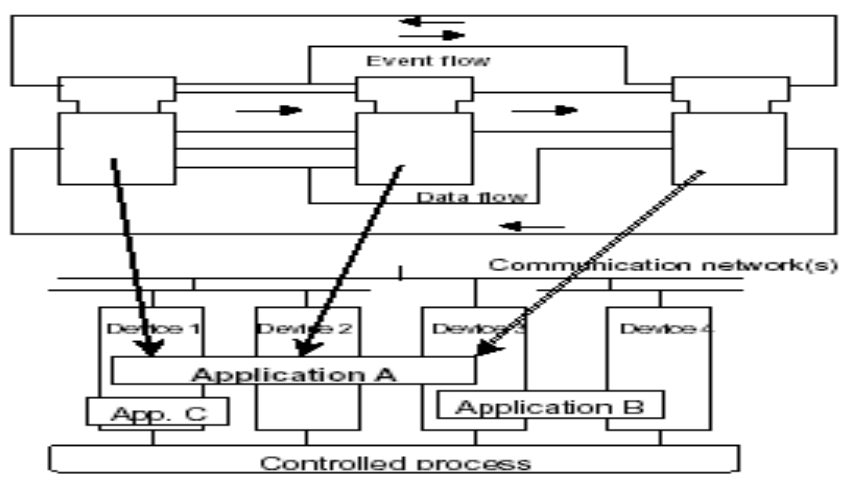

Fig 1 IEC FB based IPMCSs

\subsection{Internal Structure and Execution of Function Block}

IEC FB is defined by their inputs, outputs and contained parameters, and the algorithm that operates these parameters ${ }^{[11]}$. The input and output parameters are used to link different FBs and control FB operation, and the contained parameters are used to define FB private(or internal) data and don't participate in FB linkage. The input and output parameters consist of value and status.

FB processes its input parameters according to a specified algorithm and an internal set of contained parameters, which produce output parameters that are used in the same FB application or other FB applications. Input event to the block may affect the invocation of the algorithm, and output event may be initiated by the execution of the algorithm or response to a service request. The blocks also contain input and output parameter snap responsible for protecting parameter value from external interference (write access) while block algorithm is executing. The 
operation procedure is shown in Fig.2.

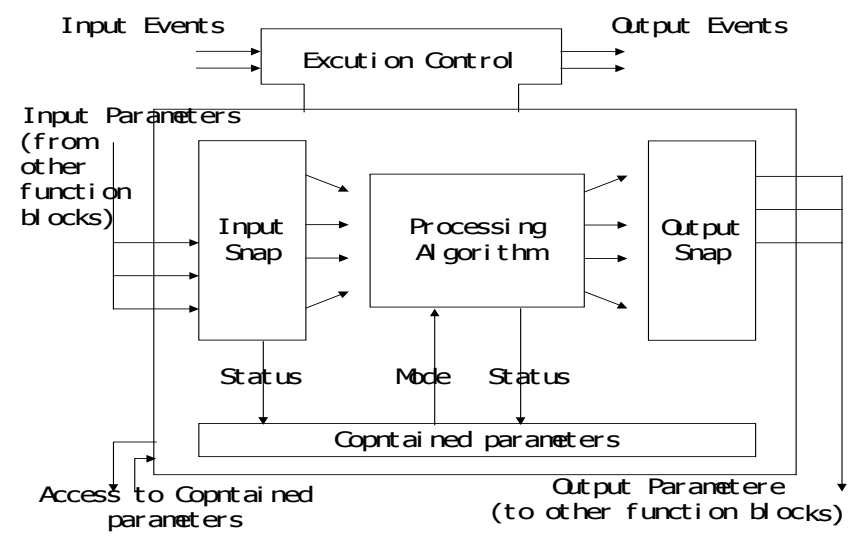

Fig 2 IEC FB Internal Structure

\subsection{Mode and Parameter Status}

The style of FB operation depends on parameter's statuses and current actual mode, which belongs to contained parameter $^{[11]}$. Under different actual modes, FB accesses different contained parameters, especially set-point, and operates in particular styles correspondingly. Fig.3 shows the basic procedure of FB, where actual mode is first determined according to the status of input parameters and target mode, then set point is gotten accordingly, and at last the output parameters is figured out based on the input parameters, actual mode and set point.

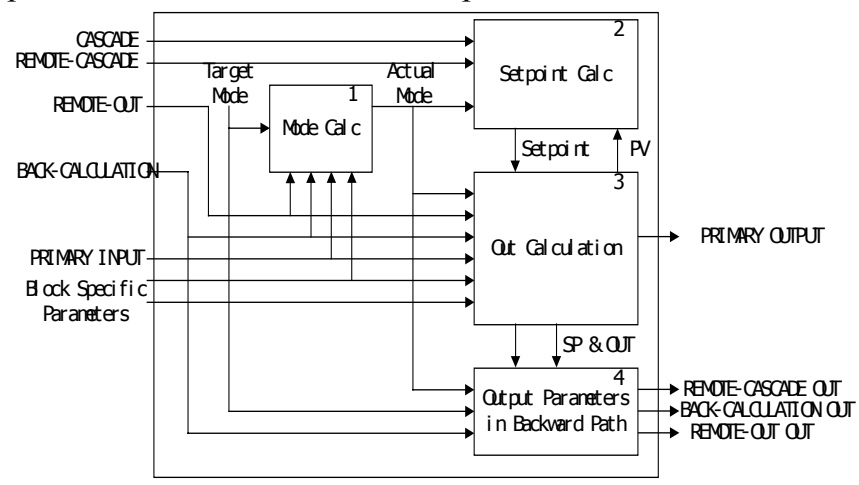

Fig 3 IEC FB Operation Procedure

\subsubsection{Parameter Status}

Parameter status is defined in input and output parameter to warrant the quality of its value and to avoid error decision caused by its unreliable value ${ }^{[11]}$. Status gives an explicit indication of four qualities Good Cascade (GC), Good No-Cascade (GNC), Uncertain (U) and Bad.

\subsubsection{Mode}

Mode, which belongs to contained parameters and is defined in all FB, determines the style of FB operation ${ }^{[11]}$. Mode is grouped into target mode, actual mode, permitted mode and normal mode, according to its role in FB operation. IEC FB operates according to actual mode, which is the current mode and is determined by target mode and operation condition, such as parameter's status. The detailed description is in [11]. Target mode, belong to one of the permitted modes, is the mode requested by the operator. Permitted mode is divided into 8 kinds of modes, and these modes have different priorities. To avoid the diffusion of actual mode caused by meeting conditions of different target modes simultaneously, the rule is set priority.

For brief, only part of the modes are introduced ${ }^{[11]}$.

$\mathrm{O} / \mathrm{S}$ : the block is not evaluated, and the output is maintained at the last value or at an assigned Fault State value.

IMan: the mode is set in response to an external tracking signal coming from a block that is closer to the final control element.

Man: the output is not being calculated and directly set by the operator through interface device.

Auto: the normal block algorithm in determining the primary output parameter uses a local set point, which is set by the operator through interface device.

Cas: in normal block algorithm, set point comes from the output of other block over link and can't be changed by the operator.

Table 1: Permitted mode

\begin{tabular}{|l|l|}
\hline Mode & Priority \\
\hline Rout(Remote Output) & 0_Lowest \\
\hline RCas(Remote Cascade) & 1 \\
\hline Cas(Cascade) & 2 \\
\hline Auto(Automatic) & 3 \\
\hline Man(Manual) & 4 \\
\hline LO(Local Override) & 5 \\
\hline IMan(Initialization) & 6 \\
\hline O/S(Out of Service) & 7 Highest \\
\hline
\end{tabular}

\subsection{The common rules of parameter's status propagation} and the mode's switch

The rules of parameter's status propagation and mode's switch under different target modes and different FBs are different. The following rules are common to all FBs and the detailed rules for specific FB or target mode is in [11].

\section{The common rules:}

1). Before initialization, the actual modes of all FBs are $\mathrm{O} / \mathrm{S}$, and their statuses of outputs are Bad.

2). On the transition out of $\mathrm{O} / \mathrm{S}, \mathrm{FB}$ will do its first actual mode evaluation on Man, then gradually transits into its target mode if its all related parameter statuses are Normal.

3). If statuses of primary input (IN) and back input (B IN) are Normal, FB transits actual mode into its target mode. Otherwise, FB transits into its corresponding safety mode.

\section{Model of Function Block and Its Application}

CPN is a high-level Petri Net and capable to describe and analyze complicated system ${ }^{[10,12]}$. Here CPN model of typical FBs and FB application are introduced.

\subsection{CPN Model of typical FBs.}

\subsubsection{AI FB with Auto Target Mode}

Table. 2 The semantics of AI CPN under Auto target mode

\begin{tabular}{|l|l|}
\hline A7 & Pre-Initialized Mode :O/S \\
\hline A4 & Intermiddle Mode: Man \\
\hline A2 & Target Mode: Auto \\
\hline
\end{tabular}




\begin{tabular}{|l|l|}
\hline T0 & External Event:Output Mode of Rsource \\
\hline T1 & Intergrade to Intermiddle Mode with unreliable output \\
\hline T2 & Intergrade to Intermiddle Mode with reliable output \\
\hline T3 & Normol operation with reliable output \\
\hline T4 T6 & Device failure with unreliable output \\
\hline P1 P6 & Output channel of message \\
\hline
\end{tabular}

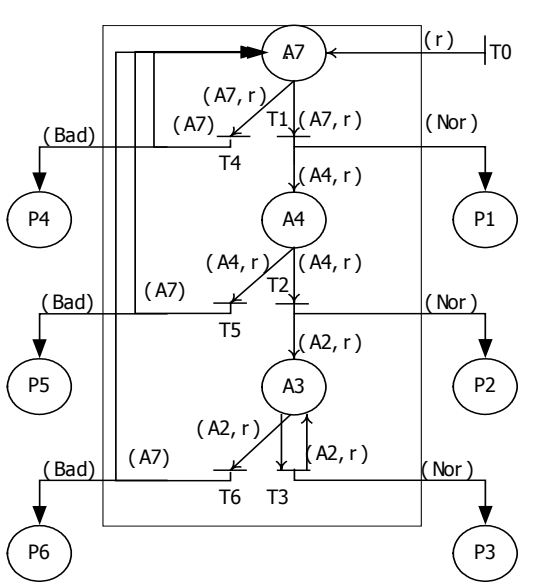

Fig 4 CPN Model of AI FB under Auto target mode

\subsubsection{PID FB with Auto Target Mode}

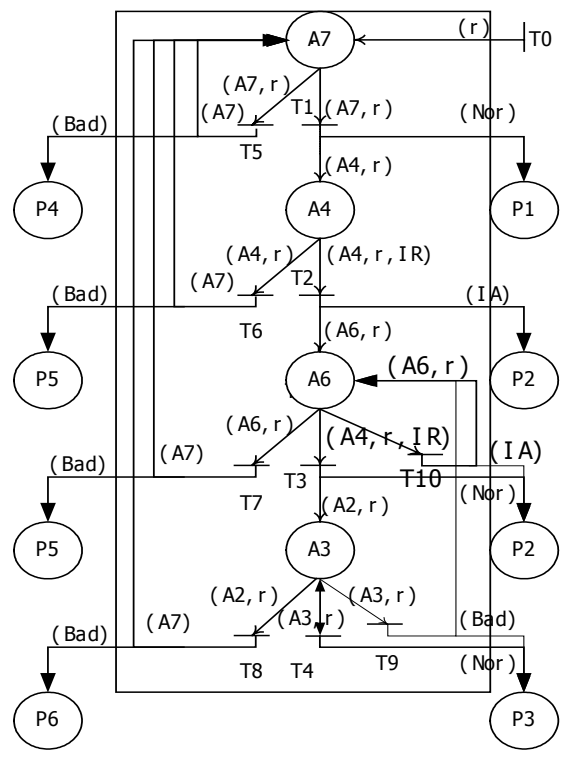

Fig.5 CPN Model of PID FB under Auto target mode

Table. 5 The semantics of PID CPN under Cas target mode

\begin{tabular}{|l|l|}
\hline A7 & Pre-Initialized Mode :O/S \\
\hline A4 & Intermiddle Mode: Man \\
\hline A6 & Adjusted Intermiddle Mode: IMan \\
\hline A2 & Target Mode: Auto \\
\hline T0 & External Event :Outputs Mode of Rsource \\
\hline T1 & $\begin{array}{l}\text { Send requirement of intialization to upper block with } \\
\text { unreliable output }\end{array}$ \\
\hline T2 & $\begin{array}{l}\text { VG Receive the response from upper block with reliable } \\
\text { output }\end{array}$ \\
\hline T3 & $\begin{array}{l}\text { Receive the Normol of lower block and inergrade to } \\
\text { target mode with reliable output }\end{array}$ \\
\hline T4 & Normol operation with reliable output \\
\hline T5 T8 & same as T4 T6.2 in table.2 \\
\hline P1 P8 & Same as P1 P6 in table.2 \\
\hline
\end{tabular}

\subsubsection{PID FB with Cas Target Mode}

Table.4 The semantics of PID CPN under Auto target mode \begin{tabular}{|l|l|}
\hline A7 & Pre-Initialized Mode :O/S \\
\hline
\end{tabular}

\begin{tabular}{|l|l|}
\hline A4 & Intermiddle Mode: Man \\
\hline A6 & Adjusted Intermiddle Mode: IMan \\
\hline A2 & Target Mode: Auto \\
\hline T0 & External Event :Outputs Mode of Rsource \\
\hline T1 & Intergrade to Intermiddle Mode with unreliable output \\
\hline T2 & $\begin{array}{l}\text { Send requirement of intialization to upper block with } \\
\text { unreliable output }\end{array}$ \\
\hline T3 & Receive the response from upper block with reliable output \\
\hline T4 & Normol operation with reliable output \\
\hline T9 & $\begin{array}{l}\text { Rcieve the Initialzation requirement from lower block } \\
\text { and response }\end{array}$ \\
\hline T10 & $\begin{array}{l}\text { Rcieve the Interrupt requirement from lower block } \\
\text { without response }\end{array}$ \\
\hline T5 T8 & Same as T4 T6 in table.2 \\
\hline P1 P8 & Same as P1 P6 in table.2 \\
\hline
\end{tabular}

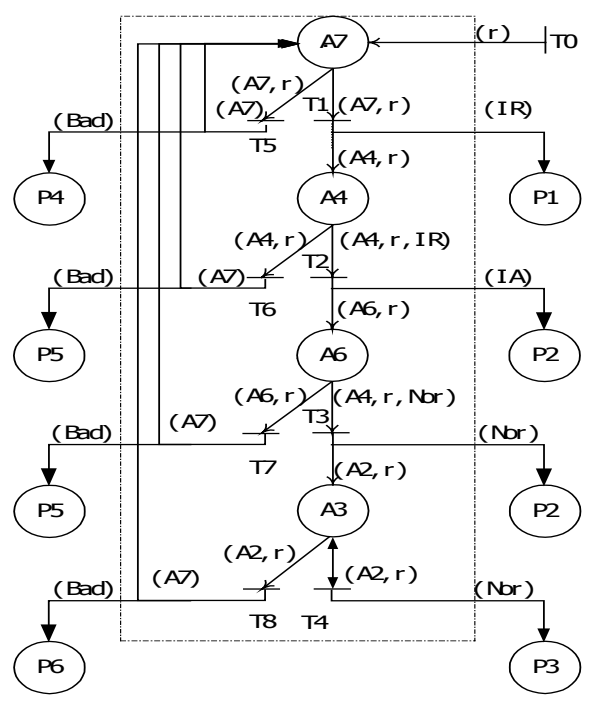

Fig.6 CPN Model of PID FB under Cas target mode

\subsubsection{AO FB with Cas Target Mode}

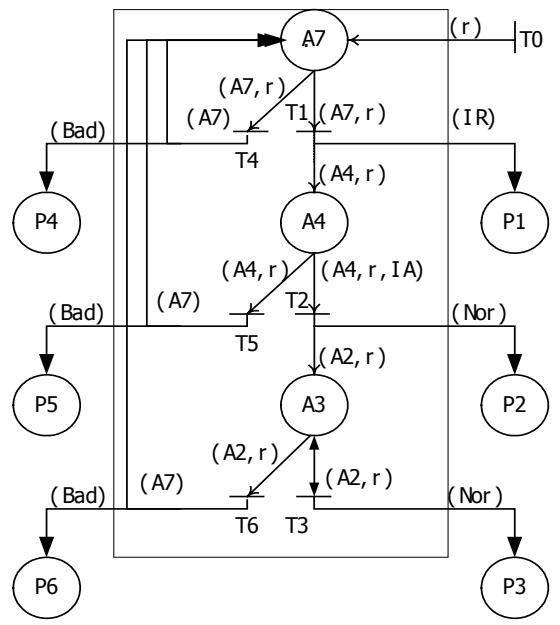

Fig.7 CPN Model of AO FB under Cas target mode

Table.6 The semantics of AO CPN under Cas target mode

\begin{tabular}{|l|l|}
\hline A7 & Pre-Initialized Mode :O/S \\
\hline A4 & Intermiddle Mode: Man \\
\hline A2 & Target Mode: Auto \\
\hline T0 & External Event:Output Mode of Rsource \\
\hline T1 & $\begin{array}{l}\text { Send requirement of intialization to upper block } \\
\text { with unreliable output }\end{array}$ \\
\hline T2 & $\begin{array}{l}\text { Receive the response from upper block with } \\
\text { reliable output }\end{array}$ \\
\hline T3 & Normol operation with reliable output \\
\hline
\end{tabular}


\begin{tabular}{|l|l}
\hline T4 T6 & Same as T4 T6 in table 2 \\
\hline P1 P6 & Same as P1 P6 in table 2
\end{tabular}

P1 P6 $\quad$ Same as P1 P6 in table 2

3.2. Model of Function Block Application: IEC FB based Boiler Water level Control System

Based on the above CPN model of FB, a CPN model of FB application, FB based Control Strategy of Boiler Water level Control System, is given here. The procedure of the FB application from its initialization to normol operation is modelled with CPN models.

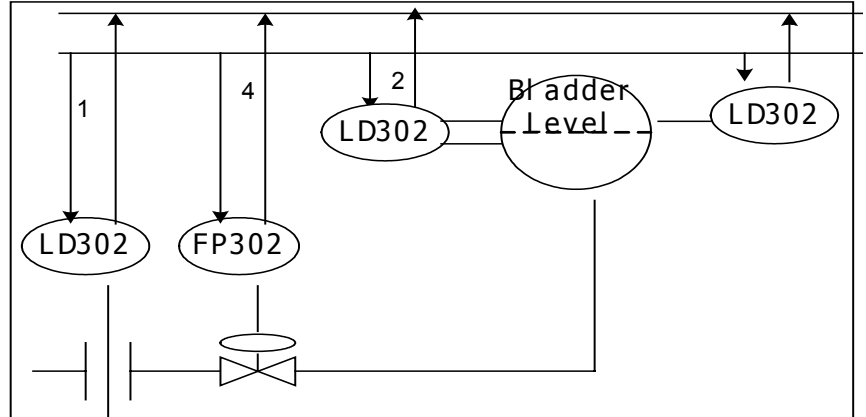

Fig 8 Physical Linkage of Boiler Water level Control System

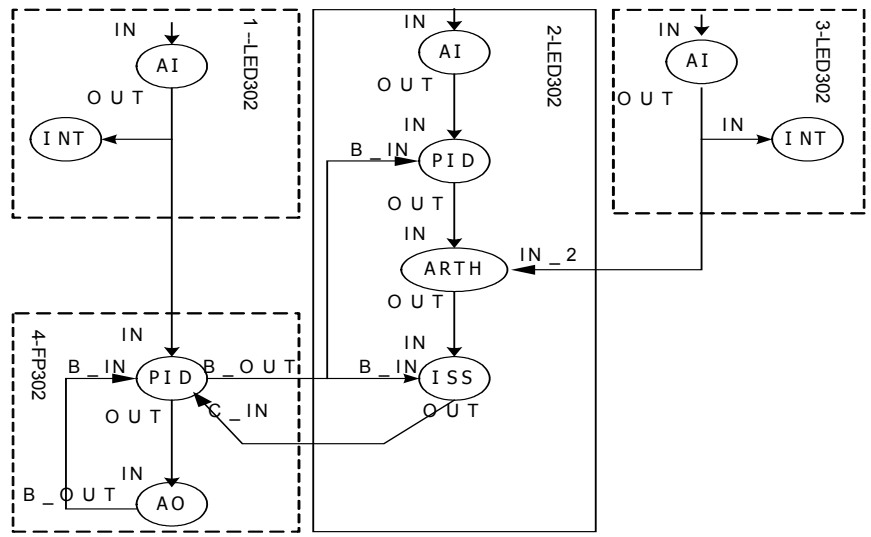

Fig 9 Control Strategy of Boiler Water level Control System

Before initialization, the actual modes of all FB in Fig.9 are $\mathrm{O} / \mathrm{S}$, and the target modes of 1.AI, 2.AI, 3.AI, 1.INT, 3. INT, 2.ARTH, 2.ISS and 2. PID are Auto, 4. PID and 4.AO are

Cas. The control strategy is explained in brief as following.

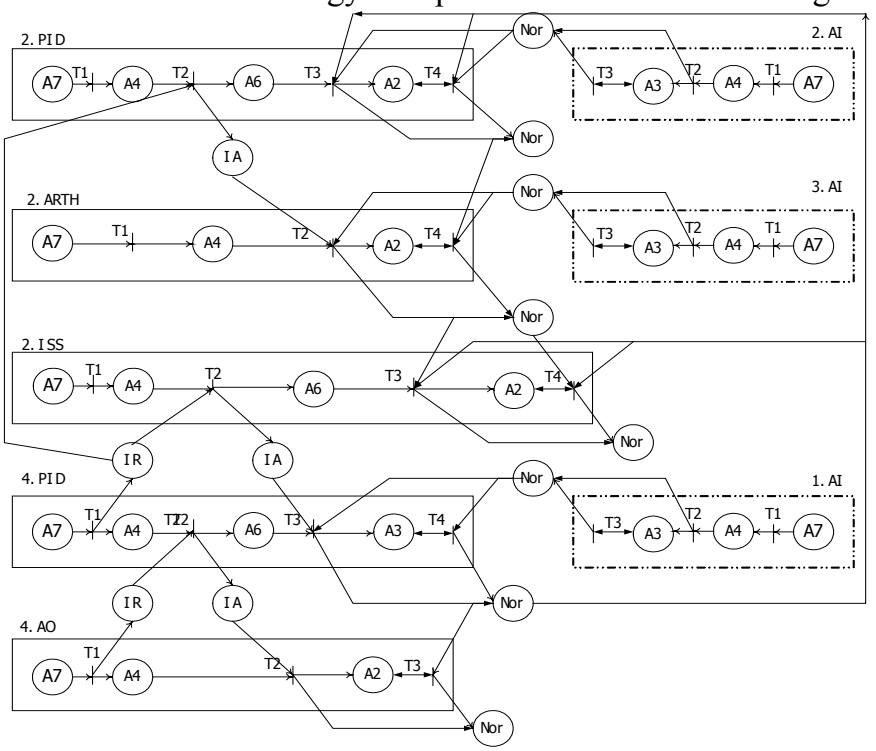

Fig.10 Initialization Procedure of Boiler Control System
1) After receiving output of 2.AI, 2.PID calculates and transmits result through output to 2.ARTH.

2) After receiving output of 3.AI and getting set-point from 2.PID, 2.ARTH calculates and transmits result to 2.ISS.

3) 2.ISS transmits feasible result to 4.PID according certain roles.

4) 4.PID calculates according to input from 1.AI, set-point from 2.ISS, and transmits result to 4. AO.

5) 4. AO controls valve by mean of 4.PID.

6) Meanwhile, 4.AO feedback control result to 4.PID and 4.PID further feedback it to 2. PID and 2.ISS. Therefore, a reliable, complete forward and backward control loop is constructed.

\section{Conclusion}

This paper presents a CPN approach to model and analyze the dynamic behavior of IEC FB. This approach is feasible since IEC FB based application can be described and analyzed clearly. Further, temporal constraints is important to IEC FB, therefore temporal behavior should be added to CPN model. Integrated control task temporal constraints and network temporal characteristics will be next works

\section{References:}

[1] R.W. Brennan, M. Fletcher, and D.H. Norrie, "An agent-based approach to reconfiguration of real-time distributed control systems," IEEE Transactions on Robotics and Automation, 18(4), pp. 444-451, 2002.

[2] R. Lewis, "Modelling Distributed Control Systems Using IEC61499", IEE 2001.

[3] J. P. Thomese, "Fieldbus and Interoperability," Control Engineering Practice, Vol. 7 (1999) 81-94

[4] Z. Wang; Z. Yue; J.M. Chen; Y.Q. Song; Y.X Sun, Realtime characteristic of FF like centralized control fieldbus and its state-of-art. IEEE ISIE. Italy, Vol.1, Pp: 140-145, 2002.07

[5] F. Xia, Z. Wang, Y.X Sun, Function Block Based Design Pattern for Flexible Manufacturing System, IEEE SMC, Washington, D.C., USA. October 5-8, 2003,

[6] Vyatkin V., Hanisch H.-M. Formal-modeling and Verification in the Software Engineering Framework of IEC61499: A way to self-verifying systems, IEEE ETFA'01, Nice, 2001

[7] V. Vyatkin, H.M. Hanisch, A modeling approach for verification of IEC1499 function blocks using Net Condition/Event Systems, IEEE ETFA, Barcelona pp.261270, September, 1999.

[8] T. Heverhagen, R. Tracht, "Integrating UML-RealTime and IEC 61131-3 with Function Block Adapters", IEEE ISORC 2001, May 2001.

[9] LiChih Wang "Modeling with Colored Timed Objected Petri Nets for Automated Manufacturing," Computer Industry Engineer Vol.34 463-480, 1998

[10] K. Jensen: Coloured Petri Nets. Basic Concepts, Analysis Methods and Practical Use. Springer-Verlag, 2nd corrected printing 1997.

[11] Function Block Application Process-Part 1, Function Specification of Function Fieldbus.

[12] Z. Wang, "Modeling and analysis of FF instrument," Chinese Journal of Scientific Instrument, 2001.03

[13] M.P Stanica, H Guéguen, A Timed Automata Model of IEC 61499 Basic Function Blocks Semantic, 15 ${ }^{\text {th }}$ Euromicro Conference on Real-Time Systems, 2003.07 